\title{
Eficacia de la cepa nativa de Bacillus subtilis como agen- te supresor del nematodo del nudo Meloidogyne spp. en cultivo de Capsicum annuum (ají pimiento piquillo)
} Effectiveness of the native strain of Bacillus subtilis as a
suppressant agent of the nematode Meloidogyne spp knot
in cultures of Capsicum annuum "piquillo pepper chili"

\author{
1Nancy Mercedes Soto Deza, ${ }^{2}$ Segundo Eloy López Medina y ${ }^{3}$ César Augusto Murguía Reyes \\ 'Bióloga; especialista en derecho ambiental; máster en biotecnología y bioingeniería; doctora en ciencias ambienta- \\ les. Universidad Nacional de Trujillo, Perú. 'Biólogo; maestro en administración de flora y fauna silvestre; doctor en \\ medio ambiente. Instituto de Papa y Cultivos Andinos-Universidad Nacional de Trujillo. La Libertad, Perú. ${ }^{3}$ Área de \\ Protección Vegetal, Universidad Nacional de Piura. Perú. \\ 1nmsotode@yahoo.es, 2segundoeloy@yahoo.es, ${ }^{3} \mathrm{~cm}$ rguiar@gmail.com
}

\section{Resumen}

En campos de cultivo infestados con Nematodos se utilizó el diseño bloques completos al azar - DBCA. Se incorporó gallinaza al $85 \%$ de pureza, 15 t/ha y $30 \mathrm{t} / \mathrm{ha}$. Se inocularon esporas de $B$. subtilis, $1 \times 10^{6} \mathrm{esp} / \mathrm{mL}$ y 2 $\times 10^{6} \mathrm{esp} / \mathrm{mL}$ a semillas de Capsicum annuum en siembra directa (ensayo I), y trasplante (ensayo II). A los 45 y a los 90 días se determinaron análisis de poblaciones de Nematodos, índice de nodulación, altura de la planta y número de frutos. Los datos se sometieron a análisis de varianza utilizando el software Statgraphics Plus 5.0. Para estimar las diferencias significativas entre tratamientos se aplicó prueba Tukey. Al inicio el ensayo I evidenció alta infestación del nematodo del nudo Meloidogyne spp., 275-27720 Nematodos/100 $\mathrm{cm}^{3}$ de suelo. En el ensayo II la evidencia fue entre 9 - 1 nemátodos $/ 100 \mathrm{~cm}^{3}$ de suelo, con diferencia significativa $(P \leq 0,05)$. La población final registrada tras la aplicación de Bacillus subtilis fue de 13 y 0 nemátodos $/ 100 \mathrm{~cm}^{3}$ de suelo; los niveles de población de Nematodos disminuyeron considerablemente: presentaron diferencia significativa $(P \leq 0,05)$. La eficacia de $B$. subtilis sobre poblaciones de Meloidogyne spp. fue evidente, pues redujo las poblaciones iniciales del nematodo, que alcanzaron una tasa de reproducción menor que 1; el índice de agallamiento no alcanzó el grado 3. La interacción de $B$. subtilis con la enmienda estiércol de gallinaza favoreció la producción alcanzada en el cultivo de Capsicum annuum.

Palabras clave: Bacillus subtilis, estiércol de gallinaza, Meloidogyne spp., Capsicum annuum, control biológico.

\begin{abstract}
In croping fields infested with nematodes, the RCBD complete blocks design was applied. $85 \%$ pure chicken manure was also incorporated, $15 \mathrm{t} / \mathrm{ha}$ and $30 \mathrm{t} /$. Spores of $\mathrm{B}$. subtilis, 1 X106 eng / mL and 2 x 106 sperm / mL Capsicum annuum seeds in direct seeding were inoculated (experiment I) and transplantation (experiment II). At 45 and 90 days analysis of nematode populations were determined, nodulation index, plant height and fruit number. The data was subjected to analysis of variance using the Statgraphics Plus 5.0 software. To estimate the significant differences between treatments, the Tukey test was applied. Initially, the study showed highly infested knot nematode Meloidogyne spp., 275 to 27720 soil nematodes $/ 100 \mathrm{~cm}^{3}$, and in Trial II it was between 9 and 1 nematodes $/ 100 \mathrm{~cm}^{3}$ of soil, with significant difference $(P \leq 0.05)$. The final population recorded after the application of Bacillus subtilis, was 13 and 0 nematodes $/ 100 \mathrm{~cm} 3$ of soil, the nematode population levels, decreased significantly, showing significant difference $(\mathrm{P} \leq 0.05)$. Efficacy of $\mathrm{B}$. subtilis on Meloidogyne spp., it was clear, reduced initial populations of the nematode, reaching a reproduction rate less than 1 , non-galling index reached grade 3 . The interaction of $B$. subtilis with poultry manure amendment favored the production achieved in the cultivation of Capsicum annuum.
\end{abstract}

Key words: Bacillus subtilis, poultry manure, Meloidogyne spp., Capsicum annuum, biological control.

\section{Introducción}

El departamento de Piura se encuentra ubicado en la parte noroccidental del Perú. Limita por el norte con Tumbes y la República del Ecuador; por el este, con Cajamarca y la 
República del Ecuador; por el sur, con Lambayeque; por el oeste, con el Océano.

El cultivo de ají pimiento del piquillo en la zona de Chapairá-Piura, viene presentando problemas, en el mes de marzo del año 2010 se inició la siembra de Capsicum annuum, una semana después del trasplante se observaron nodulaciones en las raíces, clorosis en las hojas de Capsicum annuum, se realizaron análisis con la finalidad de determinar la fuente de infección; determinándose en la Universidad Nacional de Piura, presencia de Meloidogyne spp. y otros Saprófitos, tanto en raíces como en el suelo. Durante el cultivo disminuyó la calidad y producción de la cosecha, incrementándose la aplicación de nematicidas, estas sustancias químicas por su uso elevado han provocado un incremento de $40 \%$ en los costos y alteración al ambiente.

Para el control de estos organismos se recomendó el empleo de Bromuro de metilo e híbridos resistentes (Casanova et al., 2003), pero el uso de Bromuro de metilo ha sido considerado como supresor de la capa de Ozono.

En la segunda Convención Internacional en Sistemas de Producción y Fitosanidad de Hortalizas (García, 2008), en la investigación "Manejo de Enfermedades en Hortalizas con Productos Biorracionales" se reportó que los plaguicidas químicos provocan persistencia ambiental a residuos tóxicos, generación de organismos resistentes, contaminación de recursos hídricos con degradación de la flora y fauna y crean ambientes inhabitables en el suelo para otro tipo de microorganismos que actúan de manera benéfica.

Los Nematodos Meloidogyne spp., son gusanos filiformes del grupo de los nematelmintos, con el cuerpo sin segmentar, revestidos de una piel dura (cutícula) y con simetría bilateral, de entre 1 y $3 \mathrm{~mm}$ de longitud. Penetran en las células vegetales perforando la membrana y se alimentan de su contenido. Gusanos microscópicos que suelen producir bultos en las raíces de las plantas, los llamados "rosarios" o "porrillas"; producen deformaciones, necrosis y podredumbre en los órganos vegetales especialmente del sistema radical y, en el caso de ataques graves, la progresiva reducción de los rendimientos, cuyo efecto generalmente es aducido a cansancio o fatiga del suelo y a una mala nutrición de la planta. Estos daños impiden la absorción por las raíces, traduciéndose en un menor desarrollo de la planta y la aparición de síntomas de marchitez en verde en las horas de más calor, clorosis y enanismo. Sólo especies del género Meloidogyne atacan al pimiento, produciendo marchitez y enanismo en las plantas (Incagro, 2009). La especie Meloidogyne incognita, se conoce como agallador de los nódulos o de las raíces por el tipo de lesiones que produce. Para vivir prefiere suelos sueltos y arenosos y puede completar su ciclo vital en menos de 30 días (Acosta García, 2010).

En investigaciones realizadas por Pérez Pérez (2007) en Puerto Rico, se determinó que densidades poblacionales de Meloidogyne incognita mayores a 12,000 huevos $/ J_{2}$, por tiesto causaron amarillamiento, defoliación y hasta la muerte de la planta de kenaf $(H$. cannabinus) (malvácea utilizada en la producción de papel y alimento de ganado). Perera González (2007) reporta que en el control de Nematodos de la Platanera, las poblaciones máximas de $\mathrm{Ne}$ matodos a partir de las cuales se recomienda tratamientos de control es de 1.000 Meloidogyne/100 gr de raíz. Aun así, para decidir realizar un tratamiento químico debe efectuarse un examen del conjunto de la plantación y del desarrollo radicular, ya que una correcta nutrición y riego y raíces bien desarrolladas soportan niveles superiores sin provocar daños en la producción. Asimismo aportes de materia orgánica al suelo manteniendo niveles superiores al $3 \%$ estimulan el desarrollo radicular y ejercen un efecto de control natural sobre los Nematodos.

El desarrollo y aplicación de agentes de control biológico de plagas adquiere una importancia relevante como una alternativa en el desarrollo de una agricultura sostenible que preserve los recursos naturales y el ambiente para las futuras generaciones. La aplicación controlada en agro ecosistemas de organismos vivos o sus metabolitos para el control de plagas y enfermedades, implica el mejoramiento de los cultivos, al proteger las plantas del deterioro producido por agentes fitopatógenos (Gómez et al, 2002). Los agentes biocontroladores como los organismos que interactúan con los Nematodos fitoparásitos en el suelo deben tener algunas características básicas: No deben ser patógenos de plantas, hombres o animales, capaz de reducir o suprimir eficientemente las poblaciones de $\mathrm{Ne}$ matodos por debajo del nivel crítico, capacidad de adaptación a diferentes ambientes del suelo (textura, grado de humedad, composición química y materia orgánica), buena habilidad competitiva, alto potencial de reproducción para obtener una población alta, capacidad de sobrevivir en épocas difíciles (Piedra, 2008).

Las bacterias son un grupo abundante de microorganismos del suelo sobre los cuales se ha realizado pocos esfuerzos para determinar su posibilidad de uso; las bacterias son menos conspicuas que los hongos, los efectos de los hongos en muchos casos son espectaculares y fáciles de observar, mientras que el efecto de las bacterias es más sutil y las bacterias son más difíciles de aislar y propagar que los hongos. Las bacterias que presenta un potencial como biocontrolador mayor que los hongos es la Pasteuria penetrans (Rojas, 1996), Bacillus cereus y Bacillus subtilis (Gallegos, et al. 2009). El género Bacillus incluye una importante variedad de especies Gram-positivas, no patogénicas, con propiedades antagonistas. Son buenas secretoras de proteínas y metabolitos, fáciles de cultivar y altamente eficientes para el control de plagas y enfermedades. Los mecanismos de acción de Bacillus spp., incluyen competencia por espacio y nutrientes, antibiosis e inducción de resistencia. Además, tienen comprobado efecto en la promoción de crecimiento de las plantas. La capacidad de Bacillus spp., de formar esporas que sobreviven y permanecen metabolitamente activas bajo condiciones adversas, las hace apropiadas para la formulación 
de productos viables y estables para el control biológico (Chaves Méndez, 2007). Para considerar que la bacteria sea un biocontrolador del nematodo, su ciclo de vida debe desarrollarse en sincronía con el del nematodo. Bacillus subtilis, microorganismo cuyo hábitat natural es el suelo, se encuentra ampliamente distribuido en la naturaleza. Entre sus principales características se encuentra su capacidad para formar esporas en diversas condiciones de estrés, crecer en un intervalo amplio de temperaturas (desde 15 hasta $55^{\circ} \mathrm{C}$ ), presentar motilidad, aerotaxis y velocidades de crecimiento altas, sobrevivir en concentraciones salinas (hasta el $7 \%$ de $\mathrm{NaCl}$ ), producir una amplia variedad de antibióticos y enzimas hidrolíticas extracelulares (Nakamura et al., 1999). Por otra parte el extracto no celular de B. subtilis, se reporta que también tiene un alto grado de propiedades larvicidas sobre nudos y quistes Nematodos. Fernando de Araujo y col (2009), reportaron que las endotoxinas producidas por $B$. subtilis, intervienen con el ciclo reproductivo de Nematodos, en el estadío de ovulación y eclosión de juveniles, considerando a $B$. subtilis, como supresor del nematodo formador de agallas en cultivo de tomate.

En nuestro país, no se han encontrado investigaciones específicas de control de Nematodos por bacterias en solanáceas, según investigaciones de Alcozer et al (2006), el nematodo del nudo de las raíces, Meloidogyne spp., está muy diseminado en los suelos agrícolas de los valles de Piura, siendo el uso de nematicidas químicos la principal medida de control.

En este contexto, fue necesario buscar alternativas como la utilización de productos naturales y biológicos para mejorar la productividad del ají pimiento del piquillo, minimizar el uso de productos químicos, reducir los costos y la alteración al ambiente, por lo que en el presente trabajo se evaluó la eficacia de $B$. subtilis como agente supresor del nematodo del nudo Meloidogyne sp, en el cultivo de Capsicum annuum, "ají pimiento del piquillo".

\section{Métodos}

\section{Localización}

La investigación se realizó en los campos de cultivo de la empresa Agroindustrial ECOACUICOLA SAC., ubicada en la zona de Santa Ángela, Caserío de Chapairá, distrito de Castilla, Provincia de Piura, Departamento de Piura, , zona privilegiada por su estupendo clima cálido y sus tierras fértiles, idóneas para el cultivo Capsicum annuum, o ají pimiento del piquillo durante los 365 días del año.

El trabajo se llevó a cabo en campos provenientes de siembras de Capsicum annuum, o ají pimiento del piquillo con infestación de Nematodos.

\section{Material de estudio}

- Esporas de cepa nativa B. subtilis.

- Semillas de Capsicum annuum, o ají pimiento del piquillo, del Fundo Ecoacuícola SAC.
- Suelo agrícola para el cultivo de Capsicum annuum, o ají pimiento del piquillo.

\section{Diseño de investigación}

Se aplicó un diseño DBCA: bloques completos al azar, con 9 tratamientos, 3 repeticiones y 27 unidades muestrales por tratamiento, para los ensayos I y II.

\section{Métodos}

\section{Preparación del terreno}

Según BPA (sistema EUROGAP). En cada parcela de tierra se realizó movimiento de tierra y exposición al sol (solarización natural).

Ensayo l: Se trabajó en un área de $80 \mathrm{~m}^{2}$ por parcela (conformada por 2 camas de $20 \mathrm{~m}$ lineales), para un área total de 0,270 ha, dividida en 3 bloques.

Ensayo II: Se trabajó en un área de $104 \mathrm{~m}^{2}$ por parcela (conformada por 2 camas de $29 \mathrm{~m}$ lineales), para un área total de 0.350 ha, dividida en 3 bloques. Luego se incorporó, de manera uniforme, la enmienda orgánica de estiércol de gallinaza ( $85 \%$ de pureza), en la dosis de 15 t/ha y 30 t/ha, según croquis de distribución; inmediatamente se aplicó un riego hasta conseguir la humedad de capacidad de campo.

\section{Aislamiento del inóculo}

Se aislaron, se identificaron y se cultivaron esporas de $B$. subtilis en el laboratorio de microbiología de Universidad Nacional de Trujillo (Perú).

La identificación molecular de la bacteria se realizó en el Centro de Bioinnovación de Antofagasta, de la Universidad de Antofagasta (Chile).

\section{Estandarización del inóculo}

Se obtuvo una suspensión densa de B. subtilis con agua destilada estéril, a partir de un desarrollo de la bacteria en una placa de Petri que contenía Agar Soya Tripticasa (TSA). De esta solución se hicieron diluciones hasta obtener, aproximadamente, una concentración de $1 \times 10^{6} \mathrm{esp} /$ $\mathrm{mL}$, y $2 \times 10^{6} \mathrm{esp} / \mathrm{mL}$.

\section{Formulación de las dosis}

1000000 y 2000000 de esporas $/ \mathrm{mL}$.

\section{Tratamiento}

Ensayo I: A la semilla de Capsicum annuum, o ají pimiento del piquillo, se le inocularon esporas de $B$. subtilis mediante inmersión, teniendo en cuenta el tratamiento planificado; luego se realizó la siembra directa en cada bloque según el croquis establecido y el monitoreo correspondiente.

Ensayo II: Los plantines de 30 días fueron trasplantados a condiciones de campo; se les inocularon esporas de $B$. subtilis mediante inmersión, teniendo en cuenta el tratamiento planificado y el monitoreo correspondiente.

- Materia orgánica (85\% de pureza). 


\section{Parámetros de medición}

Análisis de poblaciones del nematodo: En cada tratamiento se realizó análisis de suelo para determinar las poblaciones iniciales del nematodo antes de la aplicación de la bacteria $B$. subtilis; también, análisis de dinámica de poblaciones del nematodo a los 45 y a los 90 días de la siembra.

Las muestras de suelo se colectaron por cada bloque experimental, con un barreno de $2,5 \mathrm{~cm}$ de diámetro $\times 20 \mathrm{~cm}$ de profundidad. Luego se las mezcló con el fin de obtener la muestra final de $100 \mathrm{~cm}^{3}$ para extracción de Nematodos; se siguió con el método de tamizado de Cobb; la solución se filtró con el método del embudo de Baermann. Para la cuantificación de poblaciones del nematodo se utilizó un microscopio estereoscópico.

Índice de nodulación: Durante la cosecha se seleccionaron al azar 20 plantas por unidad experimental. Para determinar el índice de agallamiento sobre las raíces se utilizó la escala de Barker:

Análisis de la producción: Antes de la cosecha se determinó la altura de planta y el número total de frutos.

Análisis microbiológico: Presencia de la bacteria $B$. subtilis en la raíz de Capsicum annuum.

\section{Análisis de datos}

Los datos poblacionales obtenidos en las mediciones posteriores a la aplicación de los productos $\left(P_{f}\right)$ se compararon con los obtenidos de muestras previas $\left(P_{i}\right)$. Se obtuvo la tasa de reproducción (TR), que relaciona las poblaciones finales con las iniciales $\left(P_{\mathrm{f}} / \mathrm{P}_{\mathrm{i}}\right)$. Los datos de las poblaciones del nematodo, los índices de agallamiento, la altura de la planta y el número de frutos se sometieron a un análisis de varianza (ANVA), para un diseño de bloques completos al azar, utilizando el software Statgraphics Plus 5.0. Para estimar las diferencias significativas entre los tratamientos de cada experimento se realizaron análisis estadístico mediante la prueba Duncan.

\section{Resultados}

En el Ensayo I (siembra directa) la poblaciones iniciales de Meloidogyne spp., antes de la aplicación de los tratamientos variaron entre 275 y 27720 Nematodos / $100 \mathrm{~cm}^{3}$ de suelo, confirmando que los suelos presentaron altos niveles de infestación del nematodo. Después de la aplicación de la bacteria Bacillus subtilis, la población final registró valores de 13 y 0 Nematodos $/ 100 \mathrm{~cm}^{3}$ de suelo; los niveles de población de Nematodos disminuyó considerablemente, con TR de 0.0037 a 0 (Tabla 1).

El agallamiento alcanzó valores de 8 a $23 \%$, con un índice de agallamiento entre el grado 0 y 2 , presentándose diferencias significativas $(P \leq 0,05)$ entre los tratamientos (figuras 1 y 2). La altura de planta registró entre 20 y $32 \mathrm{~cm}$., la interacción respecto a la concentración de $B$. subtilis y la dosis de enmienda estiércol de gallinaza se observa en las figuras 3 y 4 . El tamaño de fruto alcanzó entre 9 a 19.5 cm., la interacción respecto a la concentración de $B$. subtilis y la dosis de enmienda estiércol de gallinaza (figuras 5 y 6 ).

Los resultados del análisis de varianza $(P \leq 0,05)$ para las poblaciones iniciales y finales de Meloidogyne spp., así como para la tasa de reproducción, muestran diferencia significativa los tratamientos aplicados (Tabla 2), corrobora la existencia de diferencias significativas la prueba Ducan $(\mathrm{P} \leq 0,05)$ (Tabla 3$)$. 
Tabla 1: Tasa de Reproducción de Meloidogyne spp y promedios del Índice de agallamiento, altura de planta y tamaño de fruto en cultivo de Capsicum annuum "ají pimiento del piquillo" con diferentes tratamientos - Ensayo I.

\section{Bacteria (esporas $/ \mathrm{mL}$ )}

\section{Estiércol (Tn/Ha)}

Tasa de Reproducción de Meloidogyne spp/100 $\mathrm{cm}^{3}$ de suelo (TR)
Agallamien- Altura plan- tamaño fruto to $(\%) \quad$ ta $(\mathrm{cm}) \quad(\mathrm{cm})$

\begin{tabular}{|c|c|c|c|c|c|c|}
\hline 0 & 0 & 1 & 0.0031 & 23 & 20 & 10 \\
\hline 0 & 0 & 2 & 0.0031 & 21 & 22 & 9 \\
\hline 0 & 0 & 3 & 0.0031 & 21 & 28 & 12 \\
\hline 0 & 15 & 1 & 0.0037 & 14 & 25 & 15 \\
\hline 0 & 15 & 2 & 0 & 14 & 26 & 16.5 \\
\hline 0 & 15 & 3 & 0.0006 & 20 & 25 & 19 \\
\hline 0 & 30 & 1 & 0.0011 & 21 & 25 & 16 \\
\hline 0 & 30 & 2 & 0.0006 & 19 & 30 & 17.5 \\
\hline 0 & 30 & 3 & 0 & 20 & 29 & 19 \\
\hline 1000000 & 0 & 1 & $0.0037^{a}$ & $14^{\mathrm{a}}$ & $25^{a}$ & 15 \\
\hline 1000000 & 0 & 2 & $0 a$ & $14^{\mathrm{a}}$ & $26^{a}$ & 16.5 \\
\hline 1000000 & 0 & 3 & $0.0006^{a}$ & $20^{a}$ & $25^{a}$ & 19 \\
\hline 1000000 & 15 & 1 & $0.0005^{\mathrm{a}}$ & $13^{a}$ & $27^{\underline{a}}$ & 16.5 \\
\hline 1000000 & 15 & 2 & $0.0001^{a}$ & $8^{\underline{a}}$ & $27^{a}$ & 14 \\
\hline 1000000 & 15 & 3 & $0.0008^{a}$ & $17^{a}$ & $27^{a}$ & 19.5 \\
\hline 1000000 & 30 & 1 & $0.0009^{a}$ & $11^{\mathrm{a}}$ & $27^{a}$ & 17 \\
\hline 1000000 & 30 & 2 & $0 a$ & $12^{\underline{a}}$ & 25 & 17 \\
\hline 1000000 & 30 & 3 & $0 a$ & $13^{\underline{a}}$ & 27 & 17.5 \\
\hline 2000000 & 0 & 1 & $0.0011^{a}$ & $21^{\mathrm{a}}$ & 25 & 16 \\
\hline 2000000 & 0 & 2 & $0.0006^{a}$ & $19^{a}$ & 30 & 17.5 \\
\hline 2000000 & 0 & 3 & $0 a$ & $20^{a}$ & 29 & 19 \\
\hline 2000000 & 15 & 1 & $0.0013^{a}$ & $17^{a}$ & 29 & 15.5 \\
\hline 2000000 & 15 & 2 & $0.0002^{a}$ & $9^{\underline{a}}$ & 29 & 15.5 \\
\hline 2000000 & 15 & 3 & $0.0327^{a}$ & $13^{a}$ & 31 & 17.5 \\
\hline 2000000 & 30 & 1 & $0.0006^{a}$ & $16^{\underline{a}}$ & 27 & 16 \\
\hline 2000000 & 30 & 2 & $0.0001^{\underline{a}}$ & $14^{\underline{a}}$ & 32 & 16.5 \\
\hline 2000000 & 30 & 3 & $0.0007 a$ & $11^{a}$ & 30 & 18 \\
\hline
\end{tabular}




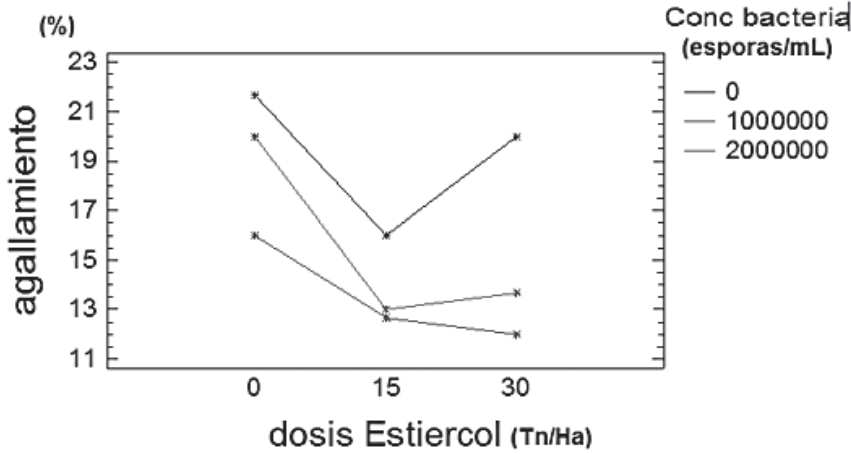

Figura 1: Interacción entre agallamiento de la raíz de Capsicum annuum "ají pimiento del piquillo", dosis de estiércol y concentración de la bacteria B. subtilis - Ensayo I

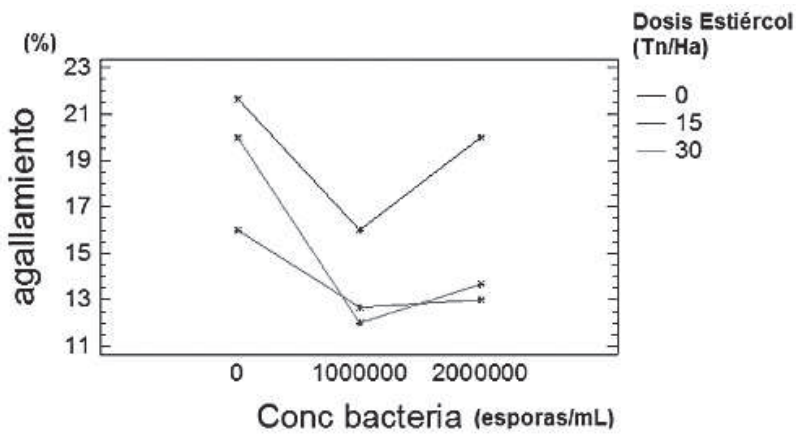

Figura 2: Interacción entre agallamiento de la raíz de Capsicum annuum "ají pimiento", concentración de la bacteria $B$. subtilis y la dosis de estiércol - Ensayo I

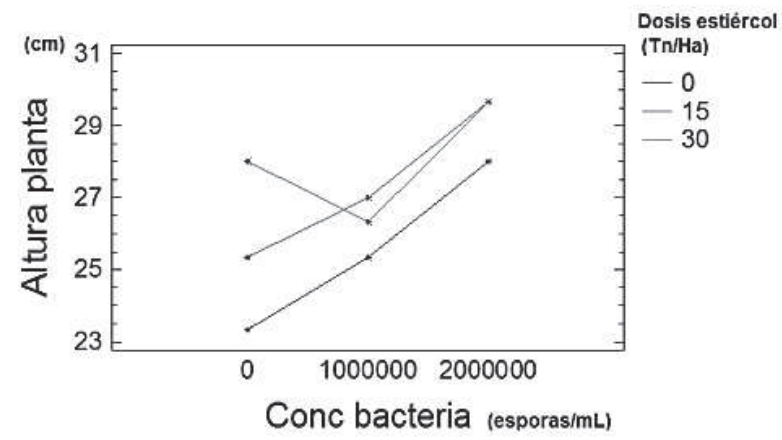

Figura 3: Interacción entre la altura de planta de Capsicum annuum "ají pimiento del piquillo", concentración de la bacteria B. subtilis y la dosis de estiércol - Ensayo I 


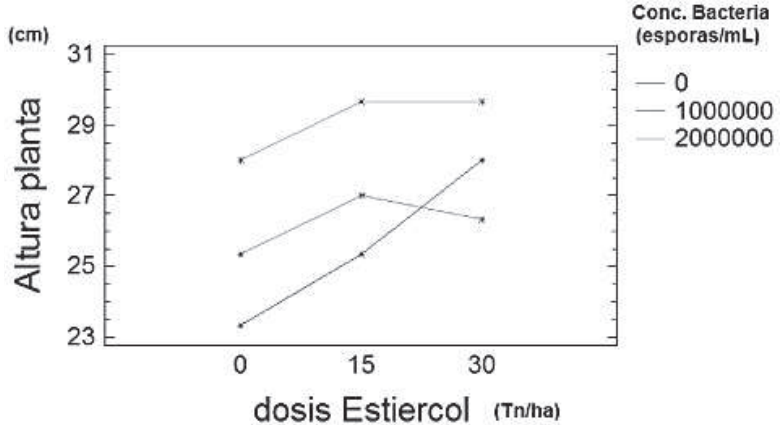

Figura 4: Interacción entre la altura de planta de Capsicum annuum "ají pimiento del piquillo", dosis de estiércol y concentración de la bacteria B. subtilis - Ensayo I.

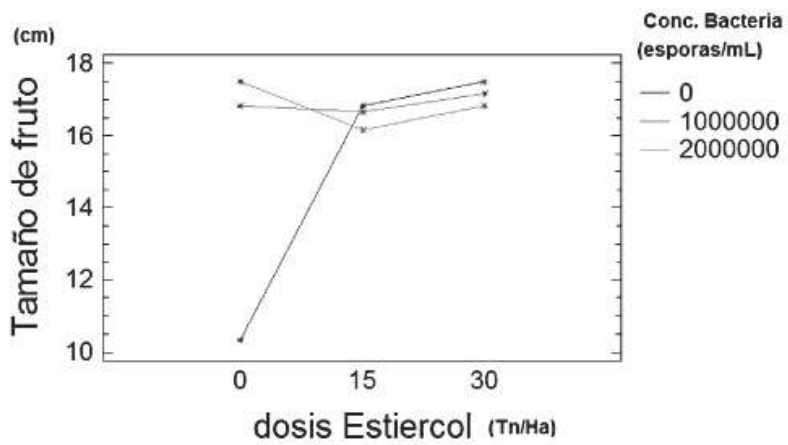

Figura 5: Interacción entre tamaño de fruto de Capsicum annuum "ají pimiento del piquillo", dosis de estiércol y concentración de la bacteria B. subtilis - Ensayo I.

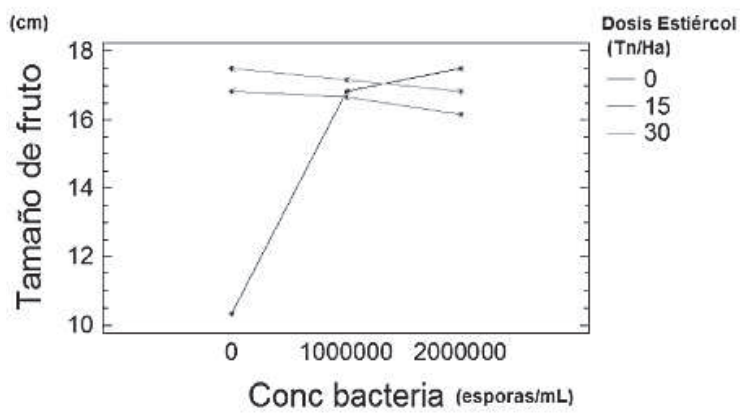

Figura 6: Interacción entre tamaño de fruto de Capsicum annuum "ají pimiento del piquillo", concentración de la bacteria B. subtilis y dosis de estiércol - Ensayo I. 
Tabla 2: Análisis ANVA del efecto de B. subtilis, y dosis de estiércol sobre poblaciones del nematodo Meloidogyne spp en cultivo de Capsicum annuum "ají pimiento del piquillo" - Ensayo I.

\begin{tabular}{|c|c|c|c|c|}
\hline \multicolumn{5}{|c|}{ POBLACIÓN INICIAL } \\
\hline Fuente & $\begin{array}{l}\text { Suma de } \\
\text { cuadrados GL }\end{array}$ & $\begin{array}{l}\text { Cuadrado } \\
\text { promedio }\end{array}$ & Cociente-F & P-Valor \\
\hline A: Conc. Bacteria & $7.60282 \mathrm{E}+07 \quad 2$ & $3.8014 \mathrm{E}+07$ & 0.67 & 0.5264 \\
\hline B: Dosis Estiercol & $3.26101 \mathrm{E}+07$ & $1.6305 \mathrm{E}+07$ & 0.29 & 0.7551 \\
\hline INTERACCIONES & $\begin{array}{l}\text { Suma de } \\
\text { cuadrados GL }\end{array}$ & $\begin{array}{l}\text { Cuadrado } \\
\text { Medio }\end{array}$ & Cociente-F & P-Valor \\
\hline$A B$ & $1.86 \mathrm{E}+08$ & $4.65 E+07$ & 0.81 & 0.533 \\
\hline Totales & $1.03 \mathrm{E}+09 \quad 18$ & $5.71 E+07$ & & \\
\hline \multicolumn{5}{|c|}{ POBLACIÓNFINAL } \\
\hline Fuente & $\begin{array}{c}\text { Suma de } \\
\text { cuadrados }\end{array}$ & $\begin{array}{l}\text { Cuadrado } \\
\text { promedio }\end{array}$ & Cociente-F & P-Valor \\
\hline A: Conc. bacteria & $21.6296 \quad 2$ & 10.8148 & 0.64 & 0.5408 \\
\hline B.: Dosis estiércol & $3.85185 \quad 2$ & 1.92593 & 0.11 & 0.8935 \\
\hline INTERACCIONES & $\begin{array}{c}\text { Suma de } \\
\text { cuadrados } \quad \text { GL }\end{array}$ & $\begin{array}{l}\text { Cuadrado } \\
\text { promedio }\end{array}$ & Cociente-F & P-Valor \\
\hline $\mathrm{AB}$ & $82.5926 \quad 4$ & 20.6481 & 1.21 & 0.3391 \\
\hline Totales & $306 \quad 18$ & 17 & & \\
\hline \multicolumn{5}{|c|}{$\mathrm{TR}=\mathrm{PF} / \mathrm{PI}$} \\
\hline $\begin{array}{c}\text { Fuente } \\
\text { A: Conc. bacteria }\end{array}$ & $\begin{array}{lr}\begin{array}{c}\text { Suma de } \\
\text { cuadrados } \\
\text { cuadra } \\
0.00005563\end{array} & \text { GL } \\
\end{array}$ & $\begin{array}{l}\text { Cuadrado } \\
\text { promedio } \\
0.00002781 \\
\end{array}$ & $\begin{array}{r}\text { Cociente-F } \\
072 \\
\end{array}$ & $\begin{array}{l}\text { P.Valor } \\
0.5020 \\
\end{array}$ \\
\hline B.: Dosis estiercol & $0.00007487 \quad 2$ & 0.00003743 & 096 & 0.4002 \\
\hline INTERACCIONES & $\begin{array}{c}\begin{array}{c}\text { Suma de } \\
\text { cuadrados }\end{array} \text { GL } \\
\end{array}$ & $\begin{array}{l}\text { Cuadrado } \\
\text { promedio }\end{array}$ & Cociente-F & P.Valor \\
\hline $\begin{array}{l}\mathrm{AB} \\
\text { Totales }\end{array}$ & 0.000174224 & 0.00004356 & 1.12 & 0.3773 \\
\hline Totales & 0.0006991218 & 0.00003884 & & \\
\hline
\end{tabular}

Tabla 3: Prueba Duncan de la Población de Meloidogyne $/ 100 \mathrm{~cm}^{3}$ de suelo, Según la Concentración de la bacteria B. subtilis - Ensayo I

POBLACION INICIAL

\begin{tabular}{|c|c|c|}
\hline \multicolumn{3}{|c|}{ POBLACION INICIAL } \\
\hline $\begin{array}{c}\text { Conc. Bacteria } \\
\text { (esporas } / \mathrm{mL} \text { ) }\end{array}$ & Recuento & Promedios \\
\hline 0 & 9 & $5046.67 \mathrm{a}$ \\
\hline 1000000 & 9 & $4966.0 \mathrm{a}$ \\
\hline 2000000 & 9 & $8565.32 \mathrm{a}$ \\
\hline \multicolumn{3}{|c|}{ POBLACIÓN FINAL } \\
\hline $\begin{array}{l}\text { Conc. Bacteria } \\
\text { (esporas } / \mathrm{mL} \text { ) }\end{array}$ & Recuento & Promedios \\
\hline 0 & 9 & $4.33333 a$ \\
\hline 1000000 & 9 & $2.55556 \mathrm{a}$ \\
\hline 2000000 & 9 & $4.55556 \mathrm{a}$ \\
\hline \multicolumn{3}{|c|}{$\mathrm{TR}=\mathrm{PF} / \mathrm{PI}$} \\
\hline $\begin{array}{l}\text { Conc. Bacteria } \\
\text { (esporas/mL) }\end{array}$ & Recuento & Promedios \\
\hline 0 & 9 & $0.00170 \mathrm{a}$ \\
\hline 1000000 & 9 & $0.000733 \mathrm{a}$ \\
\hline 2000000 & 9 & $0.004144 a$ \\
\hline
\end{tabular}

\begin{tabular}{lr} 
Contraste & Diferencia \\
\hline $0-1000000$ & 80.6667 \\
$0-2000000$ & -3518.67 \\
\hline $1000000-2000000$ & -3599.33
\end{tabular}

\begin{tabular}{lr} 
Contraste & $\begin{array}{r}\text { Diferencia } \\
1.77778\end{array}$ \\
$0-1000000$ & -0.22222 \\
\hline $0-2000000$ & -2
\end{tabular}

\begin{tabular}{lr}
\multicolumn{1}{c}{ Contraste } & Diferenc in \\
\hline $0-1000000$ & 0.000966 \\
\hline $0-2000000$ & -0.002444 \\
$1000000-2000000$ & -0.003411
\end{tabular}


En el Ensayo II (trasplante de plantines) la poblaciones iniciales de Meloidogyne spp., antes de la aplicación de los tratamientos variaron entre 9 y 1 Nematodos / $100 \mathrm{~cm} 3$ de suelo, confirmando presencia del nematodo en el suelo.

Después de la aplicación de la bacteria Bacillus subtilis, la población final registró valores de 5 y 0 Nematodos/100 cm3 de suelo; los niveles de población de Nematodos disminuyó, con TR de 5 a 0 (Tabla 4).
El agallamiento alcanzó valores de 0 a $7 \%$, con un índice de agallamiento entre el grado 0 y 2 . La altura de planta registró entre 54 y $72 \mathrm{~cm}$., la interacción respecto a la concentración de B. subtilis y la dosis de enmienda estiércol de gallinaza se observa en las figuras 7 y 8 .

El tamaño de fruto alcanzó entre 16.5 a $28 \mathrm{~cm}$., la interacción respecto a la concentración de $\mathrm{B}$. subtilis y la dosis de enmienda estiércol de gallinaza (figuras 9 y 10).

Los resultados del análisis de varianza $(\mathrm{P} \leq 0,05)$ para las poblaciones iniciales y finales de Meloidogyne spp., así como para la tasa de reproducción, muestran diferencia significativa los tratamientos aplicados (Tabla 5), corrobora la existencia de diferencias significativas la prueba Ducan $(P \leq 0,05)$ (Tabla 6).

Tabla 4: Tasa de Reproducción de Meloidogyne spp y promedios del Índice de agallamiento, altura de planta y tamaño de fruto en cultivo de Capsicum annuum "ají pimiento del piquillo" diferentes tratamientos - Ensayo II.

\begin{tabular}{|c|c|c|c|c|c|c|}
\hline $\begin{array}{l}\text { Bacteria (espo- } \\
\text { ras } / \mathrm{mL} \text { ) }\end{array}$ & $\begin{array}{l}\text { Estiércol } \\
\text { (Tn/Ha) }\end{array}$ & Bloque & $\begin{array}{c}\text { Tasa de Reproducción de } \\
\text { Meloidogyne spp/100 } \mathrm{cm}^{3} \\
\text { de suelo (TR) }\end{array}$ & $\begin{array}{c}\text { Agallamien- } \\
\text { to }(\%)\end{array}$ & $\begin{array}{l}\text { Altura plan- } \\
\text { ta }(\mathrm{cm})\end{array}$ & $\begin{array}{c}\text { tamaño fruto } \\
(\mathrm{cm})\end{array}$ \\
\hline 0 & 0 & 1 & 0 & 7 & 56 & 20 \\
\hline 0 & 0 & 2 & 0 & 0 & 54 & 22 \\
\hline 0 & 0 & 3 & 0 & 5 & 64 & 16.5 \\
\hline 0 & 15 & 1 & 0 & 2 & 58 & 20 \\
\hline 0 & 15 & 2 & 0 & 0 & 54 & 21 \\
\hline 0 & 15 & 3 & 0 & 2 & 54 & 23 \\
\hline 0 & 30 & 1 & 0 & 4 & 54 & 19.5 \\
\hline 0 & 30 & 2 & 0 & 0 & 60 & 22.5 \\
\hline 0 & 30 & 3 & 0 & 2 & 65 & 21 \\
\hline 1000000 & 0 & 1 & $0.0000 a$ & $3 a$ & $60 a$ & $20.00 a$ \\
\hline 1000000 & 0 & 2 & $0.0000 a$ & $2 a$ & $68 a$ & $23.00 \mathrm{a}$ \\
\hline 1000000 & 0 & 3 & $0.0000 a$ & $2 a$ & $54 a$ & $23.00 \mathrm{a}$ \\
\hline 1000000 & 15 & 1 & 1 & $6 a$ & $62 a$ & $23.00 \mathrm{a}$ \\
\hline 1000000 & 15 & 2 & 0 & 0 & $55 a$ & $23.50 a$ \\
\hline 1000000 & 15 & 3 & 0 & 0 & $68 a$ & $28.00 \mathrm{a}$ \\
\hline 1000000 & 30 & 1 & 5 & 9 & $68 a$ & $24.00 \mathrm{a}$ \\
\hline 1000000 & 30 & 2 & 0 & 0 & $52 a$ & $28.00 \mathrm{a}$ \\
\hline 1000000 & 30 & 3 & 0 & 0 & $72 a$ & $25.00 a$ \\
\hline 2000000 & 0 & 1 & 0 & 0 & $60 a$ & $24.00 \mathrm{a}$ \\
\hline 2000000 & 0 & 2 & $0.0000 a$ & 0 & $64 a$ & $23.00 \mathrm{a}$ \\
\hline 2000000 & 0 & 3 & $0.0000 a$ & 0 & $68 a$ & $24.00 \mathrm{a}$ \\
\hline 2000000 & 15 & 1 & $0.0000 a$ & $4 a$ & $56 a$ & $23.50 \mathrm{a}$ \\
\hline 2000000 & 15 & 2 & 0 & 0 & $60 a$ & $28.00 \mathrm{a}$ \\
\hline 2000000 & 15 & 3 & $0.0000 a$ & $7 a$ & $65 a$ & $25.00 \mathrm{a}$ \\
\hline 2000000 & 30 & 1 & $0.0000 a$ & 0 & $68 a$ & $23.00 a$ \\
\hline 2000000 & 30 & 2 & $0.0000 a$ & $1 a$ & $70 a$ & $23.00 a$ \\
\hline 2000000 & 30 & 3 & 0 & 0 & 72 & 28 \\
\hline
\end{tabular}




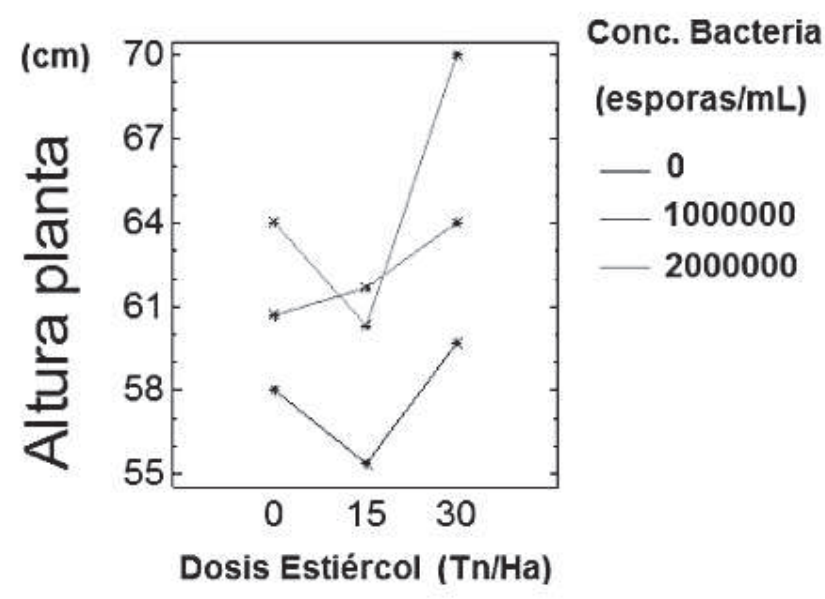

Figura 7: Interacción entre la altura de planta de Capsicum annuum "ají pimiento del piquillo", concentración de la bacteria $B$. subtilis y la dosis de estiércol - Ensayo II

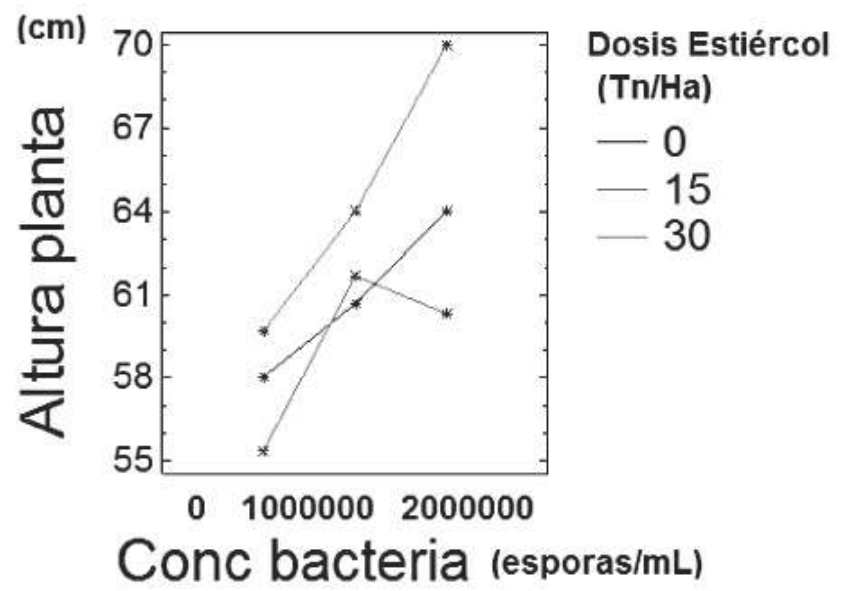

Figura 8: Interacción entre la altura de planta de Capsicum annuum "ají pimiento del piquillo", dosis de estiércol y concentración de la bacteria $B$. subtilis - Ensayo II. 


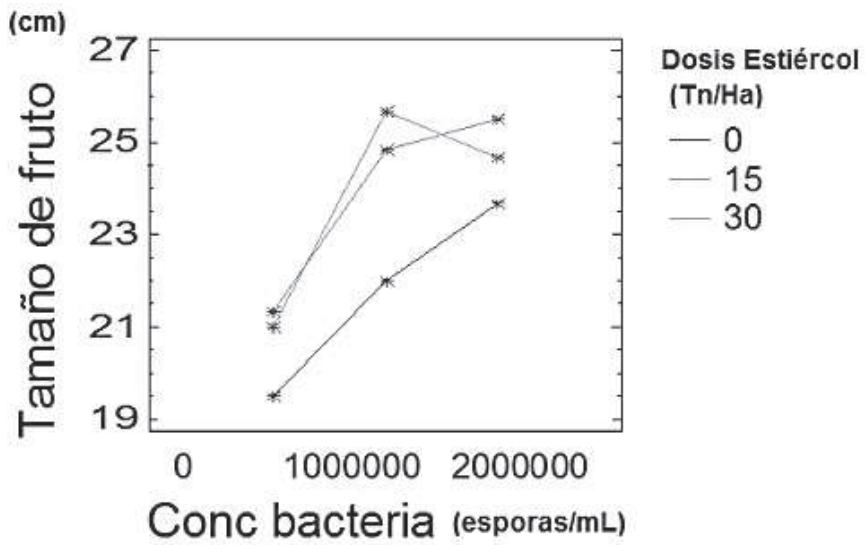

Figura 9: Interacción entre tamaño de fruto de Capsicum annuum "ají pimiento del piquillo", concentración de la bacteria $B$. subtilis y dosis de estiércol - Ensayo II.

(cm)

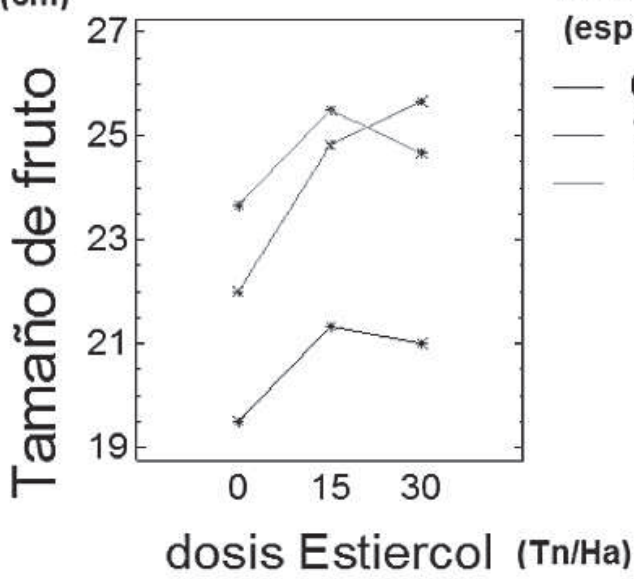

Conc. Bacteria

(esporas $/ \mathrm{mL}$ )

0

1000000

2000000

Figura 10: Interacción entre tamaño de fruto de Capsicum annuum "ají pimiento del piquillo", dosis de estiércol y concentración de la bacteria B. subtilis - Ensayo II. 
Tabla 5: Análisis ANVA del efecto de B. subtilis, y dosis de estiércol sobre poblaciones del nematodo Meloidogyne spp en cultivo de Capsicum annuum "ají pimiento del piquillo" - Ensayo II.Tabla 6: Prueba Duncan de la Población de Meloidogyne $/ 100 \mathrm{~cm}^{3}$ de suelo, Según la Concentración de la bacteria B. subtilis - Ensayo II.

\section{POBLACIÓN INICIAL}

\begin{tabular}{|c|c|c|c|c|c|}
\hline Fuente & $\begin{array}{r}\text { Suma de } \\
\text { cuadrados }\end{array}$ & GL & $\begin{array}{l}\text { Cuadrado } \\
\text { promedio }\end{array}$ & $\begin{array}{c}\text { Cociente- } \\
\text { F }\end{array}$ & $\begin{array}{c}\text { P- } \\
\text { Valor }\end{array}$ \\
\hline A: Conc. Bacteria & 11.6296 & 2 & 5.81481 & 2.09 & 0.1523 \\
\hline B: Dosis Estiercol & 3.85185 & 2 & 1.92593 & 0.69 & 0.5128 \\
\hline INTERACCIONES & $\begin{array}{r}\text { Suma de } \\
\text { cuadrados }\end{array}$ & GL & $\begin{array}{l}\text { Cuadrado } \\
\text { promedio }\end{array}$ & $\begin{array}{c}\text { Cociente- } \\
\text { F }\end{array}$ & $\begin{array}{c}\text { P- } \\
\text { Valor }\end{array}$ \\
\hline $\mathrm{AB}$ & 17.9259 & 4 & 4.48148 & 1.61 & 0.2141 \\
\hline Totales & 50 & 18 & 2.77778 & & \\
\hline \multicolumn{6}{|c|}{ POBLACIÓN FINAL } \\
\hline Fuente & $\begin{array}{c}\text { Suma de } \\
\text { cuadrados }\end{array}$ & GL & $\begin{array}{l}\text { Cuadrado } \\
\text { promedio }\end{array}$ & $\begin{array}{c}\text { Cociente- } \\
\text { F }\end{array}$ & $\begin{array}{c}\text { P- } \\
\text { Valor }\end{array}$ \\
\hline A: Conc. bacteria & 2.66667 & 2 & 1.33333 & 1.38 & 0.2758 \\
\hline B.: Dosis estiércol & 1.55556 & 2 & 0.777778 & 0.81 & 0.4614 \\
\hline INTERACCIONES & $\begin{array}{r}\text { Suma de } \\
\text { cuadrados }\end{array}$ & GL & $\begin{array}{l}\text { Cuadrado } \\
\text { promedio }\end{array}$ & $\begin{array}{c}\text { Cociente- } \\
\text { F }\end{array}$ & $\begin{array}{c}\text { P- } \\
\text { Valor }\end{array}$ \\
\hline$\overline{\mathrm{AB}}$ & 3.11111 & 4 & 0.777778 & 0.81 & 0.5363 \\
\hline Totales & 17.3333 & 18 & 0.962963 & & \\
\hline \multicolumn{6}{|c|}{$\mathrm{TR}=\mathrm{PF} / \mathrm{PI}$} \\
\hline Fuente & $\begin{array}{c}\text { Suma de } \\
\text { cuadrados }\end{array}$ & GL & $\begin{array}{l}\text { Cuadrado } \\
\text { promedio }\end{array}$ & $\begin{array}{c}\text { Cociente- } \\
\text { F }\end{array}$ & $\begin{array}{c}\text { P- } \\
\text { Valor }\end{array}$ \\
\hline A: Conc. bacteria & 2.66667 & 2 & 1.33333 & 1.38 & 0.2758 \\
\hline B.: Dosis estiércol & 1.55556 & 2 & 0.777778 & 0.81 & 0.4614 \\
\hline INTERACCIONES & $\begin{array}{r}\text { Suma de } \\
\text { cuad rados }\end{array}$ & GL & $\begin{array}{l}\text { Cuadrado } \\
\text { promedio }\end{array}$ & $\begin{array}{c}\text { Cociente- } \\
\text { F }\end{array}$ & $\begin{array}{c}\text { P- } \\
\text { Valor }\end{array}$ \\
\hline$A B$ & 3.11111 & 4 & 0.777778 & 0.81 & 0.5363 \\
\hline Totales & 17.3333 & 18 & 0.962963 & & \\
\hline
\end{tabular}

\section{POBLACIÓNINICIAL}

\begin{tabular}{|c|c|c|}
\hline $\begin{array}{l}\text { Conc. Bacteria } \\
\text { (esporas } / \mathrm{mL} \text { ) }\end{array}$ & Recuento & Promedios \\
\hline 0 & 9 & $0.444444 a$ \\
\hline 1000000 & 9 & $0.333333 a$ \\
\hline 2000000 & 9 & $1.77778 \mathrm{a}$ \\
\hline \multicolumn{3}{|c|}{ POBLACIÓN FINAL } \\
\hline $\begin{array}{c}\text { Conc. Bacteria } \\
\text { (esporas } / \mathrm{mL} \text { ) }\end{array}$ & Recuento & Promedios \\
\hline 0 & 9 & 0.0 \\
\hline 1000000 & 9 & $0.666667 \mathrm{a}$ \\
\hline 2000000 & 9 & 0. \\
\hline \multicolumn{3}{|c|}{ TR $=$ PF/PI } \\
\hline $\begin{array}{l}\text { Conc. Bacteria } \\
\text { (esporas/mL) }\end{array}$ & Recuento & Promedios \\
\hline 0 & 9 & 0.0 \\
\hline 1000000 & 9 & $0.666667 \mathrm{a}$ \\
\hline 2000000 & 9 & 0 \\
\hline
\end{tabular}

\begin{tabular}{cr}
\hline Contraste & Diferenc ia \\
\hline $0-1000000$ & 0.111111 \\
\hline $0-2000000$ & -1.33333 \\
\hline $1000000-2000000$ & -1.44444 \\
\hline
\end{tabular}

\begin{tabular}{cr}
\hline Contraste & \multicolumn{1}{c}{ Diferencia } \\
\hline $0-1000000$ & -0.666667 \\
\hline $0-2000000$ & -0.0 \\
\hline $1000000-2000000$ & 0.66666667 \\
\hline
\end{tabular}

\begin{tabular}{cr}
\hline Contraste & \multicolumn{1}{c}{ Diferencia } \\
\hline $0-1000000$ & -0.666667 \\
\hline $0-2000000$ & 0.0 \\
\hline $10000000-2000000$ & 0.6666667 \\
\hline
\end{tabular}




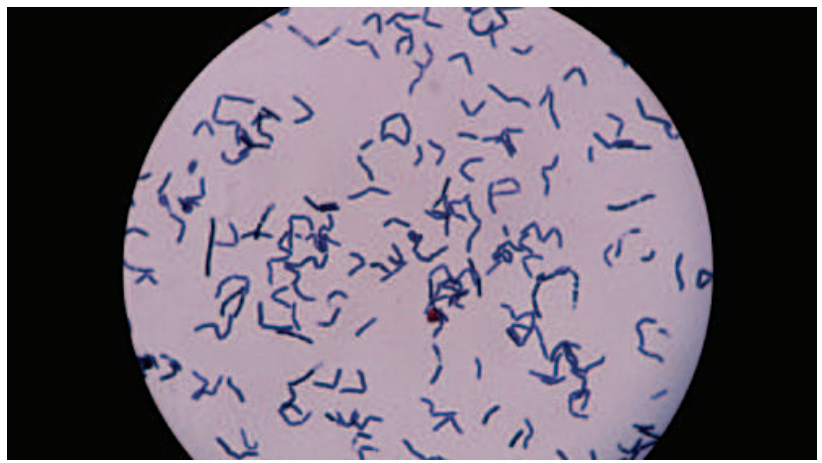

Figura 11. Observación de esporas de B. subtilis en una raíz de Capsicum annum a 1000X (coloración Gram). Ensayo I

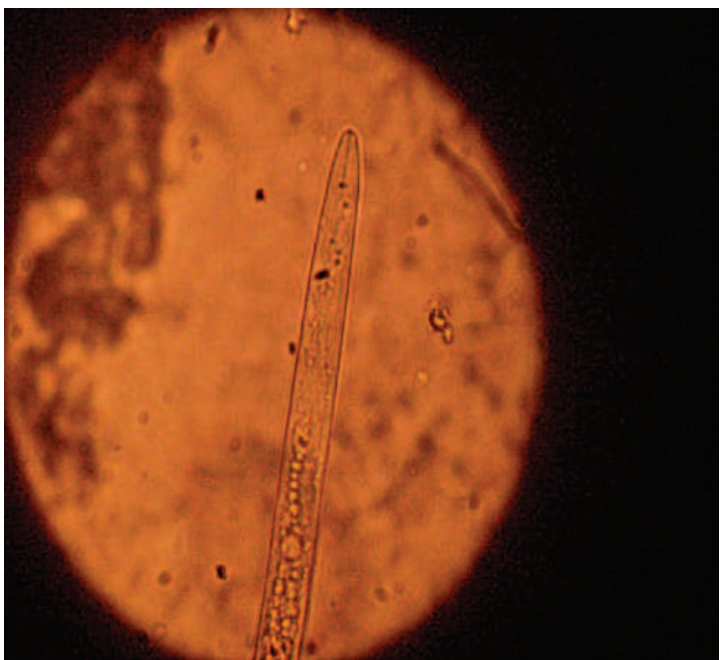

Figura 12. Observación de esporas de Bacillus adheridas a la cutícula de Meloidogyne spp. J2 a 3000X. Ensayo II

\section{Discusión y conclusiones}

En el cultivo de Capsicum annuum, anterior a la ejecución de la investigación, se evidenció presencia de clorosis y nodulaciones en las raíces; una de las causas que provoca ésta manifestación, es por infestación del nematodo Meloidogyne spp., el cual es responsable de la formación de nódulos en la raíz e interfiere en la absorción de agua y nutrientes. Después de aplicar la cepa nativa de B. subtilis, en el ensayo I y II, se observó ausencia de clorosis, evidenciando acción supresora en Meloidogyne spp. Según Pérez Pérez, (2007), las plantas enfermas presentan síntomas típicos tales como: cese del crecimiento de la planta, proliferación del desarrollo de nódulos en raíces, amarillamiento en las hojas, defoliación, culminando con la muerte en plantas, etc. La aplicación de la esporas de B.subtilis, en la semilla para la siembra directa y en los plantines para el trasplante, se hizo por inoculación, ésta estrategia es una de las más sugeridas para obtener efectividad en la disminución de poblaciones de Meloidogyne spp., de forma directa; según Gómez L. et al. (2010), indican que éste tipo de estrategia es más eficiente en el control de diversas poblaciones de Meloidogyne spp., pero requiere de más tiempo para que ocurra la selección natural, de esta forma las endosporas específicas para una determinada población de Meloidogyne presente en un área dada, se multiplicaran en su progenie.

Los resultados de ésta investigación muestran que el efecto que ejerce la bacteria $B$. subtilis sobre la población del nematodo del nudo Meloidogyne spp., está relacionada con la cantidad de esporas inyectadas; así mismo tiene interacción con la materia orgánica (estiércol de gallinaza); esto se hace evidente en el ensayo I, al aplicar el tratamiento con $1 \times 10^{6}$ esporas $/ \mathrm{mL}$ de $B$. subtilis sobre suelos con materia orgánica de $30 \mathrm{Tn} / \mathrm{ha}$, siendo la efectividad aproximado $99 \%$; comportamiento similar se registró en el ensayo II con tratamiento de $1 \times 10^{6}$ y $2 \times 10^{6}$ esporas $/ \mathrm{mL}$. Según Rojas M. T. et al. (1999), Afirman que, la eficacia de la bacteria depende en gran medida de la cantidad de esporas existentes en el suelo y de la posibilidad de que éstas se puedan adherir a la cutícula de los Nematodos para poder parasitar generaciones futuras; las esporas se pueden almacenar en el suelo y raíz seca por periodos largos sin mostrar pérdida aparente de viabilidad.

A los 90 días de aplicación de los tratamientos, se estimó la tasa de reproducción en los ensayos I y II, encontrán- 
dose comportamientos similares en los registros de población final del nematodo Meloidogyne spp, con una tasa de reproducción menor que 1 , lo cual indica el control ejercido por la bacteria $B$. subtilis; evidencia que se confirma en la menor formación de agallamiento (48\% raíces agalladas) en el Ensayo II. Así mismo de las plantas de Capsicum annum evaluadas, se encontró en la altura de planta mayor diferencia en el ensayo II del ensayo I, logrando mayor altura con el tratamiento de $2 \times 10^{6}$ (esporas $/ \mathrm{mL}$ ). Guillén Cruz R., et al (2006), infiere que algunas bacterias de Bacillus, inducen diferentes mecanismos relacionados con la promoción de crecimiento en las plantas, ya sea que proporcionen directamente nutrientes, participen en la fijación de nitrógeno, fósforo y potasio, o bien que las plantas sean capaces de producir hormonas vegetales y sustancias promotoras del crecimiento como el ácido indolacético o por la producción de antibióticos para la supresión de daños. La acción de la bacteria también interactúa con algunos factores como tipo de suelo, temperatura, fertilidad del suelo, edad de la planta, humedad, etc., es decir que la severidad de los síntomas y el desarrollo de la enfermedad causada por las especies de Meloidogyne dependen de la respuesta de la planta a la infección, tipo de suelo y condiciones del medio ambiente.

La enmienda orgánica de estiércol de gallinaza utilizada en $30 \mathrm{Tn} / \mathrm{ha}$, ha tenido un efecto positivo al interactuar con la bacteria $B$. subtilis, esto se evidenció en los niveles de poblaciones de Meloidogyne spp en el suelo, los cuales disminuyeron significativamente a los 90 días. Se conoce que la actividad de las enmiendas orgánicas incorporadas al suelo contra Nematodos parásitos de plantas puede variar con la especie del nematodo, tipo de enmienda y subproductos, de la época de la aplicación de la enmienda y de las propiedades físicas, químicas y biológicas del suelo; así el amonio liberado durante la descomposición del estiércol, tiene acción tóxica contra Nematodos parásitos. Según (Rodriguez-Kabana, 1986; Kaplan y Noe, 1993; Esnard et al., 1998), estiércoles de animal (sólidos o líquidos) y mezclas compostadas de materia animal y vegetal aplicadas en grandes cantidades antes del transplante incrementan las poblaciones de microorganismos antagonistas supresores de Nematodos. La eficacia del tratamiento y la aplicación de enmienda estiércol de gallinaza han interactuado para favorecer el cultivo de Capsicum annuum, alcanzando una producción final de $37 \mathrm{tn} /$ ha. según el manual de buenas prácticas en el manejo orgánico del cultivo de Sacha inchik (Incagro, 2009), se afirma que la agricultura orgánica es importante porque contribuye a reducir al mínimo la contaminación del ambiente, evitando los fertilizantes y plaguicidas sintéticos lo que propicia un ecosistema sostenible, alimentos seguros, buena nutrición, bienestar animal y desarrollo rural.

García (2008), afirma que la aplicación de un control natural contra las plagas, tiene ventajas como: son menos tóxicos que los químicos, por lo general son inocuos, pueden ayudar a disminuir notablemente el uso de químicos, dis- minuyen la cantidad de residuos, son efectivos en pequeñas cantidades, frecuentemente se descomponen rápido y por lo general afectan solo a la plaga objetivo.

Los resultados observados en el presente estudio demuestran que el control por $B$. subtilis representa una alternativa dentro de un sistema de manejo integrado de fitoNematodos parásitos de plantas, coincidiendo con la investigación de Siddiqui Z. y col (2001) donde se reporta, que; plantas tratadas con $B$. subtilis redujeron el agallamiento y multiplicación del nematodo $M$. incógnita, dando como resultado crecimiento vegetal mejorado.

Se concluye que; $B$. subtilis tienen efecto supresor sobre poblaciones de Meloidogyne spp en cultivo de Capsicum annuum efectivo; reduce el agallamiento y multiplicación del nematodo a una tasa de reproducción menor que 1. La interacción de estiércol de gallinaza con la cepa nativa de $B$. subtilis, probablemente mejoró la eficiencia supresora sobre Meloidogyne spp. La acción supresora B. subtilis en Meloidogyne spp, aportó a un incremento la producción de Capsicum annuum. La aplicación de la cepa nativa de $B$. subtilis, en cultivos de Capsicum annuum, es una eficaz alternativa, que se puede utilizar como parte de un programa de control biológico del nematodo del nudo $\mathrm{Me}$ loidogyne spp.

\section{Agradecimientos}

Expreso mi especial agradecimiento a: Doctores Segundo Eloy López Medina y César A. Murguía Reyes, por sus sabios consejos y orientaciones en el desarrollo del presente trabajo. A Guillermo León Arámbulo y Mario Mustafá Aguinaga, gerentes de ECOSAC, por su apoyo incondicional en la ejecución del presente trabajo. A doctora Milly Otiniano García, por su orientación en el trabajo de laboratorio. A doctor Mario Esparza Mantilla, por su apoyo en la identificación molecular de microrganismos. A Luis Bustamante, gerente agrícola de la empresa ECOSAC, y al equipo técnico que hizo posible la ejecución del plan de trabajo para el cultivo de ají pimiento del piquillo: ingeniero Jorge Espinoza Huancas, jefe de cultivos de pimientos; ingeniero Luis Bobadilla, supervisor del área en estudio; Bach.Jessica K. Valdivieso Calle, del Área de Investigación y Desarrollo; ingeniero William Saavedra, coordinador de Fertirriego Capsicums. A las Instituciones públicas y privadas que, de una $u$ otra manera, han colaborado en la presente investigación: la empresa ECOACUícOLA SAC (Piura); la Universidad Nacional de Trujillo-Facultad CCBB (Trujillo); la Universidad Nacional de Piura-Laboratorio de Nematología, Piura (Perú); la Universidad de AntofagastaLaboratorio de Biominería; el Centro de Bioinnovación y el Departamento de Acuicultura (Chile).

Doctora. Nancy Mercede Soto Deza 


\section{Literatura citada}

1. Acosta García, I. 2010.Protocolo de Prácticas. Departamento de Sanidad Animal, sección de Parasitología. Argentina.

2. Alcoser. H, J. Murguía-Córdova, C. Murguía. 2006. Efectos de solarización y enmiendas orgánicas contra el nemátodo del nudo Meloidogyne incognita bajo condiciones de vivero.Facultad de Agronomía, Universidad Nacional de Piura. Piura

3. Banco Central de Reserva del Perú. 2009. Síntesis Económica de Piura. Piura - Perú.

4. Barker, K.R. (1985). Nematode extraction and bioassays. En: K.R. Barker, C.C. Carter y J.N. Sasser (ed.). An Advanced Treatise on Meloidogyne II, pp. 27-31. International Meloidogyne Project. North Carolina State University, Raleigh, C.N.

5. Casanova, A., O. Gómez, F. R. Pupo, M. Hernández, M. Chailloux, T. Depestre y F.R. Pupo. 2003. Manual para la producción Protegida de Hortalizas. MINAG-Viceministerio de Cultivos Varios-IIHLD, La Habana, Cuba. p.112.

6. Chaves Méndez, Nancy P. 2007. Utilización de bacterias y hongos endofíticos para el control biológico del nemátodo barrenador Radopholus similis (Cobb) thorn. Programa de Educación para el Desarrollo y la Conservación. Escuela de Posgrado Univrsidad de Turrialba, Costa Rica. 98 pp.

7. Cuervo Lozada, Jeanny P. 2010. Aislamiento y Caracterización de Bacillus spp como fijadores biológicos de nitrógeno y solubilizadores de fosfatos en dos muestras de biofertilizantes comerciales. Pontificia Universidad Javeriana Facultad de Ciencias Básicas. Microbiologia Agricola y Veterinaria. Bogota. Colombia.

8. Dávila, M., N. Acosta, C. Betancourt y J. Negrón. 1999. Capacidad quitinolítica de hongos aislados de suelos agrícolas infestados con el nemátodo nodulador (Meloidogyne spp.) en Puerto Rico. J. Agric. Universidad de Puerto Rico 83(3-4): 189-199.

9. Di Rienzo, Julio Alejandro; Casanoves, Fernando; González, Laura Alicia; Tablada, Elena Margot; Díaz, María del Pilar; Robledo, Carlos Walter;Balzarini, Mónica Graciela. 2005. Estadística para las Ciencias Agropecuarias. Sexta edición. Edición electrónica.

10. Esnard, J., Marban-Mendoza, N., and Zuckerman, B. M. 1998. Effects of three microbial broth cultures and an organic amendment on growth and populations of free-living and plant-parasitic nematodes on banana. European Journal of Plant Pathology 104:457-463.

11. Fernando de Araujo, F. y Gabriel Victor Poletto Marchesi. 2009. Uso de Bacillus subtilis no controle da meloidoginose e na promoção do crescimento do tomateiro. Cienc. Rural vol.39 $\mathrm{N}^{\circ} .5$.

12. Gallegos Morales, Gabriel; Melchor Cepeda Siller, Francisco D. Hernández Castillo, Ana María Acosta Zamarripa,
Rodolfo Velásquez Valle, Ernesto González Gaona y Juan Manuel SánchezYánez. 2009. Microorganismos Benéficos Asociados a Meloidogyne incognita (Kofoid y White) Chitwood en Guayabo (Psidium guajava L.) de Calvillo, Aguascalientes, México. Rev. mex. fitopatol vol.27 $\mathrm{N}^{\circ} .2$

13. García Estrada, R. 2008. Manejo de Enfermedades en Hortalizas con Productos Biorracionales. 2da. Megaconvención Internacional en Sistemas de Producción y Fitosanidad de Hortalizas. Centro de Investigación en Alimentación y Desarrollo A.C. Unidad Culiacán. México.

14. Gómez L., H. Gandarilla y M. G. Rodríguez. 2010. Pasteuria penetrans como agente de control biológico de Meloidogyne spp.Rev. Protección Veg. Vol. 25 No. 3 (2010): 137149. Centro Nacional de Sanidad Agropecuaria (CENSA). Cuidad de La Habana, Cuba

15. Gómez, E.; Rosa M. Alvarez, A. N. San Juan1, María de los A. Zayas, Joel Hernández, Teresita Lemes, Grisel Croche y Xiomara Cruz. 2002. Nematicida a partir del hongo Verticillium lecanii Rev. Terralia No. 24

16. Guillén Cruz R., F. D. Hernández Castillo, G. Gallegos Morales, R. Rodríguez Herrera, C. N. Aguilar Gonzáles, E. Padrón Corral y M. H. Reyes Valdéz. 2006. Bacillus spp. Como biocontrol en el suelo infestado con Fusarium spp., Rhizoctonia solani Kühn y Phytophthora capsici Leonian y su efecto en el desarrollo y rendimiento del cultivo de Chile (Capsicum annuum L.). Universidad Autónoma del Estado de México. Red de Revistas Científicas de América Latina y el Caribe, España y Portugal. México. 11p.

17. INCAGRO. 2009. Manual de Buenas Prácticas Agrícolas en el Manejo Agrícola de Sacha InchiK. Lima - Perú: Ediciones Shanantina SAC.

18. Jiménez, M.A., D. Ulacio, W. Perdomo y E. Briceño. 2009. Miobiota y Nemátodos Asociados con la Rizósfera y Raíz en el cultivo de ajo (Allium sativum L.). Bioagro 21(3): 2009-216. Venezuela.

19. Kaplan, D. T., y Keen, N. T. 1993.Mechanisms conferring plant incompatibility to nematodes. Rev. Nematol. 3: 123134.

20. Khan, H. U., R. Ahmand, W. Ahmed, S. M. Khan y M. A. Khan. 2001. Evaluation of the combined effect of Paecilomyces lilacinus and Trichoderma harzianum against root-knot disease of tomato. Journal of Biological Sciences 1(3):139142.

21. López Pérez JA; Robertson L; Bello A1; Escuer M; DíezRojo MA; Piedra Buena A; Ros C; Martínez C. 2004. Resistencia en Pimiento a Nemátodos formadores de Nódulos del género Meloidogyne GÖLDI, 1892. Dpto Agroecología, Centro de Ciencias Medioambientales, C. Murcia - España.

22. Nakamura LK, MS Roberts, FM Cohan. 1999. Relationship of Bacillus subtilis clades associated with strains 168 and W23: a proposal for Bacillus subtilis subsp. subtilis subsp. Nov. and Bacillus subtilis subsp. spizizenii subsp. nov. Int. J. Syst. Bacteriol. 49: 1211-1215. 
23. Nicho S. P. 2005. Cultivo de Ají Páprika (Capsicum annuum L). Instituto Nacional de Investigación y Extensión Agraria (INIA), Donoso-Huaral. Perú.

24. Perera González, S. 2007. Los Nemátodos de la Platanera. Medidas para Su Control. AgroCabildo. Tenerife. Área de Agricultura, Ganadería, Pesca y Aguas. España. http://www.agrocabildo.org/publica/Publicaciones Acceso 06.08.2010

25. Pérez Pérez, W.M. 2007. Meloidogyne incognita y Hongos Patógenos del Suelo en el Cultivo del Kenaf (Hibiscus cannabinus).Tesis de Maestro en Ciencias en Protección de Cultivos. Universidad de Puerto Rico. Puerto Rico.

26. Piedra Naranjo, R. 2008. Manejo biológico de nemátodos fitoparásitos con hongos y bacterias. Tecnología en Marcha, Vol. 21-1, P. 123-132.

27. Puedmag Ruano, Jaime Fernando y Manuel Arnulfo Hernández Rosero. 2007. Eficiencia d Nematicidas Biológicos en el Control de Meloidogyne incognita en tomate de mesa (Lycopersicon esculentum mill.) bajo invernadero en Socapamba Imbabura. Universidad Técnica Del Norte. Ecuador.

28. Rodríguez, M., L. Gómez, R. Cuadra, L. Díaz-Viruliche, E. Fernández, A. Casanova, E. González, L. Sánchez, F. González, L. Hidalgo, O. Gómez, J.C. Hernández, T. Depestre, M. A. Hernández, X. Cruz, LI. Miranda, M. Piñón Gómez y A. Hernández. 2006. Nemátodos formadores de agallas en Sistemas de Cultivos Protegidos: Diagnostico y Manejo. MINAG. 171pp. Cuba.

29. Rodriguez-Kabana R. 1986. Organic and inorganic nitrogen amendments to soil as nematode suppressants. J. Nematol. 18:129-135.

30. Rojas M. T. y N. M. Mendoza. 1999. Pasteuria penetrans: Adherencia y parasitismo en Meloidogyne incognita y Meloidogyne arabicida. Universidad Autónoma Chapingo. México.

31. Rojas T. 1996. Consideraciones sobre Control Biológico de Nemátodos Fitoparasitos. X Congreso Nacional Agronómico. III Congreso de Fitopatología.

32. Rosimar, M. M. 2006. Manejo de nemátodos fitoparasíticos utilizando productos naturales y biológicos. Tesis de Maestría en Ciencias en Protección de Cultivos. Universidad de Puerto Rico . Puerto Rico.

33. Siddiqui, Z.A. et al. 2001. Effects of Pseudomonas fluorescens and fertlizers on the reproduction of Meloidogyne incognita and growth of tomato. Applied Soil Ecology, v.16, p.179-185

34. http://www.uco.es/dptos/zoologia/zoolobiolo_archivos/ practicas/practica_4 Con acceso el 06.08.2010

Recibido: 1 de marzo de 2012.

Aceptado: 20 de abril de 2012. 